\title{
Assessment of Sanitation Facilities at the University of Cape Coast, Ghana
}

\author{
Article by James Kojo Prah \\ University of Cape Coast Hospital, Cape Coast, Ghana \\ E-mail: james.prah@ucc.edu.gh
}

\begin{abstract}
Even though a university is a privileged institution where high level of sanitation is expected to be observed, university students continue to experience sanitation related diseases. The University of Cape Coast was plagued with outbreaks of cholera in 2015 and 2016. This study therefore aimed at assessing the sanitation facilities as well as investigating students' attitudes towards the sanitary facilities on the campus of the University of Cape Coast, Ghana.

This was a cross sectional descriptive study conducted among 422 students who resided in the university's halls of residence from January 2018 to February 2018. Both quantitative and qualitative study methods were used to collect data. A structured self-administered questionnaire was used to gather data on students' assessment of sanitary facilities on campus.

The study found the state of sanitary facilities in the halls and lecture theatres to be generally good. However, most halls were found to be overcrowded with insufficient toilets and wash rooms for students. Most of the toilets (70\%) and bath rooms (62.5\%) inspected were clean. All (100\%) of toilets had hand washing basins. Most (92.5\%) of the toilets did not have any anal cleaning materials at the time of inspection. Accommodation and sanitation facilities in the halls were found to be inadequate despite some expansions in toilets and wash rooms. Availability of soaps and anal cleaning materials was found to be inadequate. Students' bad behavior as well as inadequate number of cleaning personnel must be addressed so as to improve sanitary conditions on campus. Regular sanitation awareness campaigns and educational sessions should be organized by the environmental health section of the University Health Services to address health issues associated with poor sanitation.
\end{abstract}

Keywords: sanitation, University of Cape Coast, student, overcrowding, Ghana.

\section{Introduction}

The close relationship between sanitation and health has been well documented ever since Edwin Chadwick scientifically noted in 1842 that lack of good sanitation leads to disease. According to the World Health Organization [21], sanitation is when facilities and services are provided for the safe disposal of human excreta and urine. Lack of good sanitation has been a major cause of disease worldwide. In 2015, only $68 \%$ of the world's population had access to flush toilets and covered latrines [22]. About 2.4 billion people worldwide in 2015 did not have toilets and latrines. Out of these, about 946 million were defecating in the open. Poor sanitation accounted for about 280000 diarrhoea deaths worldwide in 2015. In sub-Saharan Africa, only $30 \%$ of the population was using improved sanitation in 2015. In Ghana, majority of the population do not have access to adequate sanitation facilities. Only $14 \%$ of the total population of Ghana was using an improved sanitation facility as of 2010 [19]. There are many diseases associated with poor sanitation. These include cholera, typhoid, polio, infectious hepatitis, ascariasis and cryptosporidiosis [16]. The second leading cause of under-five mortality globally is diarrhoeal disease. Each year diarrhoea causes 525000 child deaths worldwide [1]. In Ghana, diarrhoea diseases kill about 10000 children less than five years each year [1]. Ever since the first cholera case was reported in 1970, cases have been reported each year in Ghana [20]. In 2015, Ghana recorded 591 confirmed cases of cholera with five deaths [21]. Diseases related to poor sanitary conditions are common among students worldwide especially in developing countries like Ghana where a significant part of the population lack adequate sanitary facilities. In Ghana, the ministry of education has developed a strategic plan [8] that aims at ensuring that $100 \%$ of basic education schools have adequate hygiene systems and sanitation by 2015 and $75 \%$ of all basic schools are able to access potable water. There is however no such policy that guides the provision of 
adequate sanitary facilities in tertiary institutions in Ghana. Several studies have been conducted globally to determine the adequacy of sanitary facilities in student establishments. Most of these studies were conducted among students in basic schools $[3,4,7,9]$ and a few in institutions of higher learning $[5,11,12,13]$. Many of these studies have provided evidence for improvement in access to potable water and adequate toilet facilities. In a UNICEF study on sanitation facilities in primary schools conducted in Bangladesh (18), it was found that there was an average of one latrine for 152 pupils and as many as $13 \%$ of schools surveyed were found to have non-functional latrines. In another study conducted in Nigeria, it was reported that $27.7 \%$ of schools had no toilet facilities (15). There is however paucity of information on the state of sanitary facilities in institutions of higher learning worldwide and in particular, Ghana. In a study that assessed the level of environmental sanitation among students on the campus of the University of Ghana (11), it was revealed that environmental sanitation and waste management in the university were poor. Accommodation and sanitary facilities in the halls of residence were also found to be inadequate. In another study conducted in Ghana, factors such as absenteeism of labourers, lack of water, cleaning and refuse disposal materials contributed to sanitation problems in students' hostels at Accra Technical University (12). In a similar study conducted among Nigerian university students, irregular water supply as well as lack of waste disposal facilities were mentioned by most students as the main contributing factors to poor sanitation on campus. Among these few published studies conducted to assess sanitary facilities in universities in Ghana, none explored in detail students' attitudes towards sanitary facilities and how such attitudes affect sanitation on the various campuses. Even though the University of Cape Coast has been in existence since 1963, the state of its sanitary facilities has not been assessed and documented in detail. An outbreak of cholera in the university in 2016 heightened speculations that poor sanitary conditions coupled with overcrowding in the halls of residence as well as poor control and monitoring of food vendors might be a recipe for health hazard among students. That outbreak clearly indicated that the university might be facing major environmental sanitation challenges as well as poor hygiene behaviour among students that needs to be investigated and documented in detail. This study was therefore conducted to assess the sanitation facilities on the campus of the University of Cape Coast, Ghana, to investigate students' attitudes towards the sanitary facilities provided and to explore the possible reasons for the state of the sanitary facilities.

\section{Methods}

The study was cross-sectional in nature and used both qualitative and quantitative research methods to collect data. It was conducted among residential students of the University of Cape Coast from January 2018- February 2018. Since the expected prevalence of the variables to be studied was not known, a sample size of 422 was calculated using the formula $\mathrm{n}=\mathrm{z} \mathrm{pq} / \mathrm{d} 2$ where $\mathrm{z}$ is the normal standard deviation set at 1.96 which corresponds to $95 \%$ confidence interval, $d$ is the degree of accuracy desired set at $5 \%$ in this study, $(\mathrm{q}=1-\mathrm{p})$, and $\mathrm{p}$ was $50 \%$. The minimum sample size was adjusted to accommodate for a possible data loss of $10 \%$.

The sample size for the qualitative data was five (5) Hall Assistants (heads of cleaners) who were purposively chosen and that for the quantitative data was 422 students. Multistage sampling technique was used to recruit students from five halls of residence into the study. This sampling technique has the advantage being more accurate than cluster sampling for the same population size. It is also cost effective and time effective as compared to simple random sampling. To achieve the stated aims of this study, appropriate questionnaires and a checklist were developed from existing literature [11, 14] and validated. To ensure that items and contents in the questionnaire measure what they are designed to measure, experts evaluated the initial draft for items and materials validation. Suggestions and observations of the expert's opinions were incorporated into the final versions of the questionnaires and checklists. Analysis for reliability was carried out prior to the administration of the questionnaire. A Cronbach's alpha coefficient of 0.78 was obtained from the reliability analysis which confirmed the reliability of the questionnaire to be used as a tool for data collection. The questionnaire was developed to obtain information on socio-demographical variables, such as the respondent's age, gender, and level of education. Also, students' assessment of and attitude towards the sanitation facilities on campus were determined. 
All the data collection techniques, instruments and tools were pre-tested to assess their appropriateness, consistency and flow. The questionnaires were pre-tested on 20 students who resided in a privately owned hostel and were not part of the study.

\section{Ethical clearance}

The study proposal (Protocol ID, UCCIRB/EXT/2017/19) was reviewed and approved by the University of Cape Coast Institutional Review Board. Informed consent from respondents was obtained through the use of consent forms. Each participant was taken through the objectives, purpose and methods of the study. Confidentiality was ensured so as to protect the privacy and rights of respondents. This was done by ensuring that no names, or any form of personal identification was used. Respondents were identified by the order in which they were interviewed in each hall. A coding system as well as secured access to data were employed to ensure privacy and confidentiality.

\section{Data processing and analysis}

Data processing and statistical analysis was done manually and by the use of a computer. Data entry, verification and analysis were all done using SPSS (version 16.0).

\section{Statistical analyses}

Quantitative data were analysed with appropriate measures of centrality (mean) and dispersion (standard deviation). Frequencies and percentages were used for categorical data.

\section{Results}

There was a total of 422 respondents made up of 257 (60.9\%) males and 165 (39.1\%) females. The mean age of participants was $21.7 \pm 2.9$ SD years. The oldest student was 42 years old and the youngest 15 years. Most of the students were in the age group (20-24) years with 18 (19.7\%) of them $\leq 19$ years. The students who participated in the study were at different levels (years) of study in the university. Most of them (201, 47.6\%) were in the first year of study (level 100). The sociodemographic characteristics of respondents are summarized in Table 1.

Table 1. Socio-demographic characteristics of respondents

\begin{tabular}{|l|l|l|}
\hline Variable & $\mathrm{N}$ & $\%$ \\
\hline Age group & & \\
\hline$\leq 19$ & 83 & 19.7 \\
\hline $20-24$ & 292 & 69.2 \\
\hline $25-29$ & 37 & 8.8 \\
\hline $30-34$ & 8 & 1.9 \\
\hline$\geq 35$ & 2 & 0.5 \\
\hline Sex & & \\
\hline Male & 257 & 60.9 \\
\hline Female & 165 & 39.1 \\
\hline Marital status & & \\
\hline Single & 411 & 97.4 \\
\hline Married & 6 & 1.4 \\
\hline Co-habiting & 5 & 1.2 \\
\hline Religion & & \\
\hline Christian & 377 & 89.3 \\
\hline Moslem & 41 & 9.7 \\
\hline Traditional & 4 & 0.9 \\
\hline Academic level & & \\
\hline 100 & 201 & 47.6 \\
\hline 200 & 89 & 21.1 \\
\hline 300 & 90 & 21.3 \\
\hline 400 & 36 & 8.5 \\
\hline & & \\
\hline
\end{tabular}


DOI: $10.21522 /$ TIJPH.2013.06.03.Art009

ISSN: $2520-3134$

\begin{tabular}{|l|l|l|}
\hline 500 & 4 & 0.9 \\
\hline 600 & 2 & 0.5 \\
\hline
\end{tabular}

\section{Students' assessment of sanitation facilities on campus}

Table 2 shows the opinion of students on the state of sanitation facilities in the halls and lecture theatres. About $14.2 \%$ (60) of the students described the general cleanness of the sanitary facilities in the halls as bad whilst $75.6 \%$ (319) rated them as either average or good. Regarding the state of sanitation in the lecture halls, only 3.6\% (15) described them as excellent with $16.1 \%$ (68) rating them as bad. Only $207(49.1 \%)$ of respondents believed that toilets in the halls were cleaned regularly. Most of the students $(95 \%, 401)$ reported that the cleaners work only once a day. In the opinion of 236 (39.6\%) respondents, the main reason why toilets on campus are not always clean is students' behavior whilst $50(46.2 \%)$ assert that it is because hall cleaners do not work well. Majority of students $(195,46.2 \%)$ were of the opinion that the toilets in the halls were not sufficient for students. Most of the students $(55.5 \%, 234)$ reported there were no anal cleaning materials in the toilets. When asked to rate the sanitary conditions around food vendors on campus, most of the respondents (236, $56.2 \%$ ) gave a rating of average with $22.3 \%$ (94) saying the surroundings were bad.

Table 2. Students' assessment of sanitation facilities on university campus

\begin{tabular}{|l|l|l|}
\hline Assessment & $\mathrm{N}$ & $\%$ \\
\hline $\begin{array}{l}\text { Please rank the general cleanness of the } \\
\text { sanitation facilities in your hall/hostel }\end{array}$ & & \\
\hline Bad & 60 & 14.2 \\
\hline Average & 153 & 36.3 \\
\hline Good & 166 & 39.3 \\
\hline Excellent & 43 & 10.2 \\
\hline $\begin{array}{l}\text { Please rank the general cleanness of the } \\
\text { sanitation facilities in your lecture halls }\end{array}$ & & \\
\hline Bad & 68 & 16.1 \\
\hline Average & 186 & 44.1 \\
\hline Good & 153 & 36.3 \\
\hline Excellent & 15 & 3.6 \\
\hline $\begin{array}{l}\text { Are the toilets in the hall/hostel cleaned } \\
\text { regularly? }\end{array}$ & & \\
\hline Yes & 207 & 49.1 \\
\hline Sometimes & 170 & 40.3 \\
\hline No & 45 & 10.7 \\
\hline $\begin{array}{l}\text { How many times are the toilets cleaned in a } \\
\text { day? }\end{array}$ & & \\
\hline Once & 401 & 95.0 \\
\hline Twice & 19 & 4.5 \\
\hline Thrice & 2 & 0.5 \\
\hline $\begin{array}{l}\text { What is the main reason why toilets on campus } \\
\text { are not always clean? }\end{array}$ & & \\
\hline Students' behavior & 236 & 39.6 \\
\hline Cleaners not working well & 50 & 46.2 \\
\hline Water does not always flow & 136 & 32.2 \\
\hline $\begin{array}{l}\text { Are the toilets in the hall/ hostel sufficient for } \\
\text { students? }\end{array}$ & & \\
\hline Yes & 167 & 39.6 \\
\hline No & 195 & 46.2 \\
\hline Don't know & 60 & 14.2 \\
\hline Is soap and water always available for hand & \\
\hline & & \\
\hline
\end{tabular}




\begin{tabular}{|l|l|l|}
\hline washing after using the toilet/urinal? & & \\
\hline Yes & 79 & 18.7 \\
\hline Sometimes & 132 & 31.3 \\
\hline No & 211 & 50.0 \\
\hline Are there anal cleaning materials at the toilets? & & \\
\hline Yes & 85 & 20.1 \\
\hline Sometimes & 103 & 24.4 \\
\hline No & 234 & 55.5 \\
\hline $\begin{array}{l}\text { How will you rate the sanitary conditions } \\
\text { around food vendors on campus? }\end{array}$ & & \\
\hline Bad & 94 & 22.3 \\
\hline Average & 237 & 56.2 \\
\hline Good & 78 & 18.5 \\
\hline Excellent & 13 & 3.1 \\
\hline
\end{tabular}

\section{Attitudes of students towards sanitation facilities}

With regards to their attitudes towards the sanitation facilities provided in the halls, $45.5 \%$ (192) said they hated using the facilities whilst 5.9\% said they avoided using the facilities altogether. A few students $(9,2.1 \%)$ confessed that they sometimes use the nearby bushes instead. Most respondents $(41.2 \%, 174)$ said they had no problems using the facilities provided at the lecture halls. Table 3 gives a summary of the attitudes of students towards sanitation facilities on campus.

Table 3. Attitudes of students towards sanitation facilities

\begin{tabular}{|l|l|l|}
\hline Attitude & $\mathrm{N}$ & $\%$ \\
\hline $\begin{array}{l}\text { What is your attitude towards using the sanitation facilities in } \\
\text { hall/hostel? }\end{array}$ & & \\
\hline I don't have any problem using them & 185 & 43.8 \\
\hline I hate going there but I have no choice & 192 & 45.5 \\
\hline Sometimes I use the nearby bush & 9 & 2.1 \\
\hline Sometimes I avoid going there & 25 & 5.9 \\
\hline I avoid going there altogether & 11 & 2.6 \\
\hline $\begin{array}{l}\text { What is your attitude towards using the sanitation facilities in your } \\
\text { lecture halls? }\end{array}$ & & \\
\hline I don't have any problem using them & 174 & 41.2 \\
\hline I hate going there but I have no choice & 158 & 37.4 \\
\hline Sometimes I use the nearby bush & 11 & 2.6 \\
\hline Sometimes I avoid going there & 51 & 12.1 \\
\hline I avoid going there altogether & 28 & 6.6 \\
\hline
\end{tabular}

\section{In-depth interview with hall assistants}

All Hall Assistants interviewed $(5,100 \%)$ said the halls were overcrowded and this was having a negative toll on the sanitary facilities provided. When asked about the main challenges they face in providing good sanitation to students, their responses were as follows: student attitudes $(5,100 \%)$, inadequate human resource $(3,60 \%)$, and erratic water supply $(4,80 \%)$. About the students' attitudes, they mentioned that students were not flushing toilets after use, were choking wash hand basins with food particles, substances such as sanitary pads were being flushed through the drains eventually choking them. Also, students misused soaps and anal cleaning materials provided even stealing them. With regards to the number of cleaners in the halls, most of the Hall Assistants $(4,80 \%)$ described the situation as bad. On the average, there was one cleaner to 10 toilets. All of them said the cleaners work twice a day and do not work on weekends and national holidays. 


\section{Observations made on sanitary facilities in halls of residence}

Trained investigators inspected 40 wash rooms in all 5 halls of residence. All the toilets were water closets. Most of the toilets (70\%) and bath rooms (62.5\%) inspected were clean. All of toilets had hand washing basins. Most $(92.5 \%)$ of the toilets did not have any anal cleaning materials at the time of inspection. Only a few (7.5\%) had toilet rolls available. The average students per room were found to be 4 with an average of 14 students per toilet. Large water storage tanks and several waste bins were seen in all the halls visited.

\section{Discussion}

Most of the respondents (60.9\%) were males and were in the age group of 20-24 years. These findings were consistent with the pattern of higher education in Ghana as revealed in earlier studies $[11,12]$. Most of the participants $(47.6 \%)$ were level 100 students. This was probably because of the policy of the University of Cape Coast to give first year students priority with regards to University accommodation.

Results of this study showed a mixed reaction to the state of sanitation in the halls of residence by students. Majority of the students (39.3\%) rated the general cleanness of the sanitary facilities in the halls as good whilst a significant proportion $(14.2 \%)$ said it was bad. Similar findings were made in a study among students of the University of Ghana [11]. Sanitation facilities in many schools worldwide have been found to be deplorable [7, 2]. The students complained about the work of cleaners in the halls. Majority of the respondents (46.2\%) cited cleaners not working well as the main reason why the toilets were not usually clean and that they clean the toilets only once a day. This assertion by the students was disputed by the heads of the cleaners who insisted that the cleaners work twice in a day. They however do not work on weekends and national holidays. It is therefore possible that even though the cleaners were supposed to work twice a day, many of them do not and only work once as observed by many of the students. Therefore, supervisors of these cleaners must intensify their supervision so as to ensure that the cleaners work as expected of them. In the absence of the cleaners during weekends and holidays some of the students volunteer to clean the toilets. This situation is a recipe for an outbreak of a sanitation related disease among the students. The university authorities should therefore recruit more cleaners and also compensate them for working on weekends and public holidays.

A significant proportion (39.6\%) of students however admitted that students' behavior is to be blamed for the usually unclean state of the toilets. This finding is consistent with what was found in a similar study conducted among Nigerian university students in which as many as $78.3 \%$ of respondents agreed that students' behavior contributed to the poor sanitary conditions in student hostels [13]. This finding also corroborates what the Hall Assistants said about students' attitudes that contribute to the unsanitary situations in the wash rooms. This calls for behavioral change among such students. Studies have shown that interventions to promote sanitation behavioral change include community-based approaches, social marketing, messaging and theory-based approaches [3]. The community-based approach could be used in this student community. In this approach a culture of cooperation and ownership is created. Thus, through durbars, students should be educated on the health effects of poor sanitary habits and why it is to their benefit to ensure that their environment is kept clean. They should also be allowed to make inputs into how sanitation on campus can be improved.

Most of the students complained that the toilet facilities in the halls were not sufficient for them. The inadequacy of residential facilities to match the rapidly increasing student population has compelled hall authorities to allocate rooms that were designed to accommodate a maximum of two students to four students. This has happened without corresponding increases in the number of toilet facilities. The sanitation situation in the halls of residence confirms the assertion by WHO/AFRO (2006) that fast increasing populations are usually characterized by inadequate water and sanitation facilities and services [23]. The overcrowding situation in the halls puts all the students at some health risks. Such health risks include reduced quality of life due to increased physical contact, lack of sleep, lack of privacy and poor hygiene practices [6]. Most respondents said soap and water as well anal cleaning materials were not always available. This finding was confirmed by the research team that 
did not find any soap or anal cleaning materials provided for use in most of the toilets inspected during the study. According to Hall Assistants this was because of students' behavior as they usually misuse them and even steal them. In a study that investigated an outbreak of Hepatitis A in a school, it was found out that major factors that contributed to the outbreak included lack of toilet papers, hand towels, and soap for hand washing (17). Therefore, in order to prevent outbreaks of sanitation related diseases, university authorities should ensure regular supply of toilet papers, soap and water in all wash rooms.

\section{Conclusions}

Accommodation and sanitation facilities in the halls were found to be inadequate despite some expansions in toilets and wash rooms. Probable reasons for the poor state of some of the sanitary facilities found in the study included inadequate supply of soaps and anal cleaning materials and erratic water supply. Students' bad behaviors such as not flushing toilets after use and the misuse and even stealing of soaps and anal cleaning materials were also found to contribute significantly to the state of sanitary facilities on campus. In order to improve students' attitude, authorities must ensure that all regulations on sanitation are enforced. Punitive actions should be taken against students who flout such regulations so as to instill in them self-discipline and sanitation consciousness. Student's hand books should contain information on how to properly use sanitary facilities on campus and how to maintain them. There should be regular sanitation awareness campaigns and educational sessions organized by the environmental health section of the University Health Services that will address health issues associated with poor sanitation. Hall and University authorities are to be commended for providing large water storage tanks for use by students, however, adequate number of cleaning personnel should be recruited to ensure that the halls are cleaned thoroughly throughout the week including weekends and public holidays.

\section{Limitations of study}

The main limitation to this study was the cross sectional nature of the study. It is therefore impossible to draw conclusions about cause and effect even though it can be used to make inference about associations. The generalization of these findings is limited only to the University of Cape Coast. Since responses to the survey instrument were self-reported, students may give answers that are socially desirable and may not reflect their practices in reality. Another challenge was the use of observation, a subjective form of assessment. The study was not able to determine enabling factors that might have contributed to the hygiene behavior of the students. An understanding of the factors that influence hygiene behavior is important so that very effective policies could be developed to improve hygiene behavior among university students.

\section{References}

[1]. Asamoah, A., Ameme, D.K., Sackey, S.O., Nyarko, K.M., \& Afari, E.A. (2016). Diarrhoea morbidity patterns in Central Region of Ghana. Pan Afr Med J. 25(Suppl 1): 17.

[2]. Cao, H., Fujii, H., \& Managi, S. (2015). A productivity analysis considering environmental pollution and diseases in China. Journal of Economic Structures, 4(1):1-9.

[3]. De Buck, E., Van Remoortel, H., Hannes, K., Govender, T., Naidoo, S., Avau, B., Vande Veegaete, A., et al. (2017). "Approaches to Promote Handwashing and Sanitation Behaviour Change in Low- and MiddleIncome Countries: A Mixed Method Systematic Review." Campbell Systematic Reviews 7: 1-447.

[4]. Egbinola, C.N., \& Amanambu, A. C. (2015): Water supply, sanitation and hygiene education in secondary schools in Ibadan,Nigeria. In: Szymańska, D. and Środa-Murawska, S. editors, Bulletin of Geography. Socioeconomic Series, No. 29, Toruń: Nicolaus Copernicus University, pp. 31-46. DOI: http://dx.doi.org/10.1515/bog-2015-0023.

[5]. Fadairo, G. \& Adedeyi Y.M.D. (2012). The menace of public toilets in institutional housing: case studies of selected universities in south-west Nigeria. WIT Transactions on Ecology and The Environment, 160: 126135.

[6]. Gray, A. "Definitions of crowding and the effect of crowding on health" (2001). Ministry of Social Policy, New Zealand. Retrieved 3 February 2018. 
DOI: 10.21522/TIJPH.2013.06.03.Art009

ISSN: $2520-3134$

[7]. Gyabaah, D., Awauh, E., \& Ackerson, N.O.B. (2009). Sanitation in Basic Schools - A Case study in Tano South District. Accessed at https://www.ircwash.org/.../sanitation-basic-schools-case-study-tano-south- districtpaper-prepared-west-africa on 24/2/18.

[8]. Ghana education service- school health education programme unit wash in schools (WinS). Annual report 2012.

[9]. Jasper, C., Le T., \& Bartram, J. (2012). Water and sanitation in schools: a systemic review of the health and educational outcomes. Int. J. Environ. Res. Public Health.

[10]. Koopman, J.S. (1978). Diarrhoea and school toilet hygiene in Cali, Colombia. Am. J. Epidemiol. 107:412420.

[11]. Mahama, E.E. (2009). Assessment of environmental sanitation and disease among students in University of Ghana, Legon. Accessed at ugspace.ug.edu.gh/handle/123456789/8760 on 23/2/18.

[12]. Mensah-Kuffour, A.G., \& Gablah, G.P. (2017). Sanitation in Accra Technical University Hostel and Its Environs: A Case Study of Accra Technical University Old Hostel. Hospitality \& Management, 2(1):1-12.

[13]. Musa, R.M., \& Haque, M. (2016). Assessment of factors contributing to poor environmental sanitation in university's male hostel. International journal of pharmaceutical research 8(3):59-63

[14]. Nansereko, F. (2010). Adequacy and utilization of sanitation facilities in Mpigi District. Accessed at https://news.mak.ac.ug/documents/.../NANSEREKO_Fatumah.pdf.

[15]. Ofovwe, G., \& Ofili, A. (2007). Knowledge, attitude and practice of school health programs among head teachers of primary schools in Ego Local Government Area of Edo State, Nigeria. Annals of African medicine 6(3):99-103.

[16]. Prüss, A., Kay, D., Fewtrell, L., \& Bartram, J. (2002) Estimating the burden of disease from water, sanitation, and hygiene at a global level. Environmental Health Perspectives, 110:537-542.

[17]. Rajaratnam, G., Patel, M., Parry J.V., Perry, K.R., Palmer, S.R. (1992). An outbreak of hepatitis A; School toilets as a source of transmission. J. Public Health Med. 14:72-77.

[18]. UNICEF (United Nations Children's Emergency Fund), Bangladesh, (2012). Water, Environment and Sanitation. Available at: http://www.unicef.org/bangladesh/wes.html accessed at 31/05/18.

[19]. UNICEF. (2012). Pneumonia and Diarrhoea - Tackling the deadliest diseases for the world's poorest children. Retrieved from https://www.unicef.org/publications/index_65491.html.

[20]. UNICEF Ghana. (2016). Accessed at https://www.unicef.org/ghana/wes.html.

[21]. WHO -Situation Report on Cholera Outbreak in Ghana. 24 May 2015. Accessed at https://reliefweb.int/report/ghana/ghana-cholera-mdrgh010-dref-review-report.

[22]. WHO (2016). Sanitation fact sheet. Accessed at http://www.who.int/en/.

[23]. WHO/AFRO (2006). The Health of the People the African Regional Health Report. WHO, 20 Avenue Appia, 1211 Geneva 27, Switzerland. 